\title{
París en el imaginario poético de Italo Calvino
}

\author{
Luigi CARMELITANO \\ Departamento de Filología Italiana \\ Universidad Complutense de Madrid \\ luigicarmelitano@hotmail.com
}

Recibido: $01 / 02 / 2013$

Modificado: $09 / 07 / 2013$

Aceptado: 19/09/2013

\section{Resumen}

Este artículo analiza la incidencia que la ciudad de París tuvo en el imaginario poético de Italo Calvino, revisando textos representativos de su producción narrativa y ensayística, sin dejar aparte el papel que esta capital ha significado en su biografía. Aparece el rostro de una ciudad polifacética, donde abundan las referencias literarias y culturales, que influyen directamente en el imaginario poético calviniano hasta fecundar profundamente su escritura en prosa.

Palabras clave: Calvino, París, eremita, isla, Palomar.

Title: Paris in the poetic imaginary of Italo Calvino

\section{Abstract}

This article analyzes the impact of the city of Paris in poetic imagery of Italo Calvino, reviewing some of his most representative fictions and essays, without leaving aside the role that this capital has played in his biography. It emerges a multifaceted city full of literary and cultural references, which have a deep influence on Calvino's poetic imaginary, thus resulting very productive for his writing prose.

Keywords: Calvino, Paris, hermit, island, Palomar.

\section{Índice}

1. Introducción

2. Eremita a Parigi

3. París en Palomar

4. Conclusión

A Daniela S., por todo lo que hemos compartido 


\section{Introducción}

París vista a través de los ojos de Italo Calvino es una ciudad que ostenta los rasgos de su vida pasada y que quiere ser reconocible más por estos rasgos que por su presente contemporáneo. El escritor italiano la explora, la investiga, la recorre tanto en la vida real como en la página escrita, hasta ponerla bajo una lupa convirtiéndola en objeto de un análisis atento y minucioso. En Eremita a Parigi y en el ensayo La città-romanzo in Balzac, París se presenta como la ciudad de la cultura por antonomasia, museo de museos, enorme obra de consulta, con todas sus tiendas, calles, edificios, habitantes, que pueden ser leídos como se leen las distintas entradas que se suceden en la composición de una enciclopedia.

Una breve revisión de las metáforas, a través de las cuales Calvino mira a la capital francesa, permitirá determinar los obstáculos que le impiden al escritor italiano formarse una imagen personal de ella. Imagen que sólo una lectura más detallada permitirá identificar con una "isla", con todas las implicaciones que esta conlleva sobre la relación entre escritura y vida. Por fin, la investigación sobre unos textos pertenecientes a Palomar determinará la relevancia de las experiencias parisinas en contribución a la arquitectura de una obra construida en el límite entre la ficción y la autobiografía.

\section{Eremita a Parigi}

Para Calvino, el primer contacto con París fue literario: "Prima che una città del mondo reale, Parigi, per me come per milioni d'altre persone d'ogni paese, è stata una città immaginata attraverso i libri, una città di cui ci si appropria leggendo" (Calvino 1994a: 190). Solo en un segundo momento su conocimiento sobre la ciudad se profundiza directamente, cuando decide mudarse allí con toda su familia en 1967 y en donde se quedará hasta 1980.

Curioso es que la vida en París no haya sido de inmediato generadora de textos que la tengan como protagonista, 0 , por lo menos, escenario ideal de sus escritos. Calvino mismo se interroga sobre este punto al principio de su reflexión sobre la relación que posee con la capital francesa, titulada Eremita a Parigi ${ }^{1}$ (Calvino 1994a: 190-199):

Da alcuni anni ho una casa a Parigi, e vi passo una parte dell'anno, ma finora questa città non compare mai nelle cose che scrivo. Forse

1 El texto fue publicado por primera vez en forma limitada en 1974, en Lugano (Suiza italiana), por la editorial Edizioni Pantarei. La primera versión italiana se imprime en 1994, junto a otros textos autobiográficos, recopilados por voluntad de la mujer de Italo Calvino, Esther Singer Calvino, dando el título a la totalidad de la obra. Ahora se encuentra disponible también en el III volumen Romanzi e racconti de la versión "I Merdidiani" Mondadori (Calvino 1994b: 102-110). 
per scrivere di Parigi dovrei staccarmene, esserne lontano: se è vero che si scrive sempre partendo da una mancanza, da un'assenza. Oppure esserci più dentro, ma per questo dovrei averci vissuto fin dalla giovinezza: se è vero che sono gli scenari dei primi anni della nostra vita che danno forma al nostro mondo immaginario, non i luoghi della maturità. (Calvino 1994a: 190)

El contacto directo entre Calvino y París se configura entonces bajo una omisión, un silencio, que para nosotros resulta sin duda más revelador que cualquier palabra, porque la imposibilidad de escribir del lugar en el cual vive lleva a Calvino a investigar las razones que le impiden transformar dicho lugar en un paesaggio interiore: "[...] Bisogna che un luogo diventi un paesaggio interiore, perchè la immaginazione prenda ad abitare quel luogo, a farne il suo teatro" (Calvino 1994a: 190). Para Calvino la interiorización del paisaje significa transformarlo en algo personal, tiene que pasar por una asimilación progresiva que resulta todavía más difícil en el caso de París, dado que ha sido "il paesaggio interiore di tanta parte della letteratura mondiale, di tanti libri che abbiamo letto, che hanno contato nelle nostre vite" (Calvino 1994a: 190).

Parece entonces que el silencio es debido a esta incapacidad de hablar de París de forma personal sin ser influido por la literatura pasada: si el primer contacto con la ciudad de París ha sido a través de las páginas literarias, será difícil decir algo nuevo sobre ella, algo que todavía no haya sido escrito, sin necesariamente tener en mente los autores y los textos que ya han tratado el tema. Calvino logrará hacerlo muy tarde en su carrera literaria, cuando en Palomar, obra publicada en 1983, unos cuadros de la ciudad de París entrarán en el tejido de un proyecto más amplio llevado al límite del rigor filosófico (cfr. apartado 3). Un destino que la ciudad de París parece compartir con la ciudad de Roma, donde Calvino se mudó una vez dejada la capital francesa y donde residirá hasta su muerte en 1985: "Altra città di cui non sono capace di parlare, Roma; altra città di cui si è scritto troppo" (Calvino 1994a: 192). Dos capitales cuyas imágenes resultan dificilmente asimilables por la prosa calviniana, casi como si el silencio denunciase un "empacho estilístico", un impedimento debido a la dificultad de tratar las dos ciudades bajo un aspecto nuevo, dado que todo sobre ellas ha sido ya dicho y por eso, no es necesario repetirse.

Si la rápida seña dedicada a Roma vive a lo largo de una similitud, otra comparación, esta vez por contraste, conecta París con la ciudad que Calvino siempre privilegió, considerandola como su ciudad favorita, es decir Nueva York:

Qualche volta mi è venuto spontaneo di ambientare racconti del tutto immaginari a New York, città in cui ho vissuto solo pochi mesi in vita 
mia: chissà, forse perché New York è la città più semplice, almeno per me, più sintetica, una specie di prototipo di città: come topografia, come aspetto visuale, come società. Mentre invece Parigi ha un grande spessore, ha tanta roba dietro, tanti significati. Forse mi dà un po' soggezione: l'immagine di Parigi, dico, non la città in sé, che anzi è la città che appena uno ci mette piede la sente subito familiare. (Calvino 1994a: 191)

Justamente la comparación hace resaltar las valencias implícitas y opuestas en la manera de mirar a estas dos ciudades: Nueva York le gusta a Calvino porque su configuración la acerca mucho a un modelo de ciudad ideal, cuya ramificación por calles ortogonales corresponde a una aspiración de precisión y de claridad muy ambicionada por el escritor italiano ${ }^{2}$. Al contrario, París es una ciudad tan densa de estratificaciones simbólicas y culturales que casi se necesita un desglose o un mapeo para desenvolverse en ella. Tarea que el escritor italiano se propone implicitamente en Eremita a Parigi: catalogar unas cuantas significaciones que suscita la imagen de la ciudad de París para luego intentar recabar y definir una imagen personal de ella, descubrir la significación última que conecta su vivencia privada a esta ciudad. Tarea más difícil, justamente porque la inmersión constante y cotidiana en la vida parisina condiciona su visión y su imaginario (fundamental la distinción final entre imagen de París y ciudad en sí), igual que la influencia de las lecturas de los autores que ya han tratado del tema.

Así que de momento, allá por el año 1973, Calvino se limita a reservar sus reflexiones a las páginas autobiográficas, o a hablar de la ciudad de París a través de los autores que lo han precedido. Es el caso de Honoré de Balzac, autor de Ferragus, para el cual Calvino había escrito una Nota introduttiva en la edición italiana de la novela salida en 1974. En esta introducción, Calvino admira a Balzac por haber transformado su obra en la novela de la ciudad de París, así que fácilmente puede declarar que en Ferragus se actúa "la fondazione d'una mitologia della metropoli" (Calvino 1995: 779).

\footnotetext{
2 En la "Intervista di Maria Corti", Calvino declaraba: "La città che ho sentito come la mia città più di qualunque altra è New York. Una volta ho perfino scritto, imitando Stendhal, che volevo che sulla mia tomba fosse scritto 'newyorkese'. Questo avveniva nel 1960. Non ho cambiato idea, per quanto da allora in poi abbia vissuto la più parte del tempo a Parigi, città dalla quale non mi stacco che per brevi periodi e dove forse, potendo scegliere, morirò. Ma New York ogni volta che ci vado la trovo più bella e più vicina a una forma di città ideale. Sarà anche che è una città geometrica, cristallina, senza passato, senza profondità, apparentemente senza segreti; perciò è la città che dà meno soggezione, la città che posso illudermi di padroneggiare con la mente, di pensarla tutta intera nello stesso istante" (Calvino 1994a: 277). Sobre la relación entre Calvino y Nueva York, véase también la entrevista titulada "La mia città è New York", en particular la página conclusiva (Calvino 1994a: 270).
} 
Fare diventare romanzo una città: rappresentare i quartieri e le vie come personaggi dotati ognuno di un carattere in opposizione con gli altri; evocare figure umane e situazioni come una vegetazione spontanea che germina dal selciato di queste o quelle vie, o come elementi di così drammatico contrasto con esse da provocare cataclismi a catena; far sì che in ogni mutevole momento la vera protagonista sia la città vivente, la sua continuità biologica, il mostroParigi: questa l'impresa cui Balzac nel momento in cui comincia a scrivere Ferragus si sente chiamato. (Calvino 1995: 775)

Balzac ha sido capaz de transformar París en la verdadera protagonista de su novela, que sólo aparentemente parece policíaca. La lectura de Calvino se exalta a la hora de seguir detalladamente la génesis de la obra, que coincide con un progresivo descarte de todos aquellos materiales ajenos que no contribuyeran a la construcción de la imagen de la capital francesa como una ciudad-monstruo, donde todo, hasta la caracterización de los personajes, depende de la pertenencia a la ciudad misma.

Quel che ora appassionava Balzac era il poema topografico di Parigi, secondo l'intuizione che egli per primo ebbe della città come linguaggio, come ideologia, come condizionamento d'ogni pensiero e parola e gesto, dove le vie "impriment par leur physionomie certaines idées contre lesquelles nous sommes sans défense", la città mostruosa come un gigantesco crostaceo di cui gli abitanti non sono che le articolazioni motorie. Già da anni Balzac andava pubblicando sui giornali bozzetti di vita cittadina, medaglioni di personaggi tipici: ora punta su una organizzazione di questo materiale, su una specie di enciclopedia parigina... (Calvino 1995: 777)

Ciudad como novela, lenguaje, o como enciclopedia: son estos los puntos de comparación que seguramente Calvino tiene en mente a la hora de elaborar su propia visión. La capital francesa en sí misma se presta a ser interpretada según estas imágenes gracias a su gran carga de referencias culturales, conjunto imprescindible y connatural de ella. El escritor italiano reconoce esta particularidad y exclusividad de París en el momento en que elabora un verdadero inventario de las tiendas de la capital francesa en Eremita a Parigi. Un inventario tan arraigado en su imaginario que llegará a trasladarlo, con oportunos cambios, a Palomar.

Potrei dire allora che Parigi, ecco cos'è Parigi, è una gigantesca opera di consultazione, è una città che si consulta come una enciclopedia: ad apertura di pagina ti dà tutta una serie di informazioni, di una ricchezza come nessuna altra città. Prendiamo i negozi, che costituiscono il discorso più aperto, più comunicativo che una città esprime: tutti noi leggiamo una città, una via, un tratto di 
marciapiede seguendo la fila dei negozi. Ci sono negozi che sono il capitolo di un trattato, negozi che sono pagine di giornale. A Parigi ci sono negozi di formaggi dove vengono esposti centinaia di formaggi tutti diversi, ognuno etichettato col suo nome, formaggi avvolti nella cenere, formaggi con le noci: una specie di museo, di Louvre dei formaggi. [...] Ecco che se domani mi metto a scrivere di formaggi, posso uscire a consultare Parigi come grande enciclopedia dei formaggi. (Calvino 1994a: 196)

En París, las tiendas de quesos (sobre las cuales Calvino escribirá Il museo dei formaggi, en la sección "Palomar fa la spesa" de Palomar), "certe drogherie in cui si riconosce ancora quello che era l'esotismo del secolo scorso" (Calvino 1994a: 196), los numerosos cines del Quartier Latin donde "ogni spettatore puo ricostruire la fortuna del cinema pezzo a pezzo" (Calvino 1994a: 198) son todos elementos aunados por esta posibilidad de ser leídos como voces de una inmensa enciclopedia, o como un museo, contenedor de piezas que tienen sobre el cliente, visitante, o espectador, un poder de sugestión tan poderoso como para trasladarnos a un momento del pasado, a un fragmento de la historia o a un pasaje de la civilización que los ha generado.

$C^{\prime}$ è un tipo di negozio in cui si sente che questa è la città che ha dato forma a quel particolare modo di considerare la civiltà che è il museo, e il museo a sua volta ha dato la sua forma alle più varie attività della vita quotidiana, cosicché non c'è soluzione di continuità tra le sale del Louvre e le vetrine dei negozi. Diciamo che nella strada tutto è pronto per passare al museo, o che il museo è pronto per inglobare la strada. (Calvino 1994a: 196-197)

Es como si hubiera un proceso osmótico entre la capital francesa y las piezas que la componen: todos los elementos que participan en la composición de este cuadro, es decir París, sus museos y sus tiendas, parecen pertenecer a un conjunto único où tout se tient, cuya característica precisa es la calidad propia de cada elemento de significar otra cosa que sí mismo ${ }^{3}$. Una ciudad así connotada podría tranquilamente entrar en la serie de aquellas ciudades que componen la sección de "Le città e i segni" en la obra Le

${ }^{3}$ El sucederse de metáforas a través de las cuales Calvino ve la capital francesa se extiende hasta incluir la idea de una París "come un libro dei sogni, come un album del nostro inconscio, come un catalogo di mostri" (Calvino 1994a: 197), donde el movimiento artístico-literario del surrealismo ha encontrado terreno fértil para desarrollarse y dejar a su vez el rastro del propio pasaje. A esta se añade la imagen de París como "gigantesco ufficio degli oggetti smarriti, un po' come la luna dell'Orlando Furioso dove si raccoglie tutto ciò che è stato perduto al mondo" (Calvino 1994a: 198), porque en París "puoi sempre sperare di trovare ciò che avevi perduto, il passato proprio o altrui" (Calvino 1994a: 198). 
città invisibili (Calvino 1972), en la cual Calvino ha logrado concentrar en el único simbolo de la ciudad toda su investigación literaria conducida a principio de los años setenta. Así que la imagen de la ciudad de París podría colocarse junto al perfil de una ciudad como Tamara, donde "I'occhio non vede cose ma figure di cose che significano altre cose" (Calvino 1972: 21) y donde "lo sguardo percorre le vie come pagine scritte" (Calvino 1972: 22), metáfora, la de la calle que puede ser leída como una página escrita, que pasa en Eremita a Parigi invariada.

Solo logrando el final de este texto, Calvino llega a reconocer el significado verdadero que la capital francesa ha tenido en su historia personal:

[...] la mia Parigi è la città della maturità: nel senso che non la vedo più con lo spirito di scoperta del mondo che è l'avventura della giovinezza. Sono passato nei miei rapporti col mondo dall'esplorazione alla consultazione, cioè il mondo è un insieme di dati che è li indipendentemente da me, dati che posso confrontare, combinare, trasmettere, magari ogni tanto moderatamente goderne, ma sempre un po' dal di fuori. (Calvino 1994a: 199)

Para quien como Calvino percibe este cambio en su vida determinado por el paso de la juventud a la madurez, la ciudad de París corresponde plenamente a una exigencia de consulta del mundo, como se consultan los libros de una biblioteca. $Y$ de hecho esto coincide con una modalidad de escritura calviniana que pasa, curiosamente en concomitancia con su mudanza a París, desde la capacidad de escribir obteniendo lo necesario desde el fondo de sus memorias, de su recuerdos, de sus vivencias, hasta la capacidad de dejarse inspirar sólo por textos, sólo por la intermediación de otros libros para consultar. Antes el mundo era una realidad para ser vivida en primera persona, ahora es una totalidad de signos que pueden ser consultados más que vividos: "[...] anche il mondo è diventato qualcosa che io consulto di tanto in tanto, ecco che tra questo scaffale e il mondo di fuori non c'è quel salto che sembra" (Calvino 1994a: 195).

Si este fil rouge conecta indisolublemente en el mismo sentido París, la condición del escritor y su manera de escribir, seguramente su presencia en la capital francesa habrá actuado de acelerador de este paso desde la exploración hacia la consulta del mundo. Además, Calvino ha sido capaz de hablar de estos momentos transformándolos en dos figuras: la del eremita, que justifica el título del texto en examen, y la del cazador de dragones. El primero es el símbolo del hombre que se aparta del caos de la vida cotidiana para concentrase en sus estudios en un lugar solitario. El segundo es el símbolo de la 
vida vivida enteramente, de la implicación en primera persona en el mundo. Lo confirma Calvino en esta declaración:

Nel capitolo finale del Castello confronto la figura dell'eremita con quella del cavaliere uccisore di draghi. Ecco negli anni '70 sono stato soprattutto l'eremita. In disparte, ma mica lontanissimo [...] L'eremita ha la città sullo sfondo, per me la città resta I'Italia. Parigi è più simbolo di un altrove che un altrove. E poi sarà proprio vero cha abito a Parigi? Un discorso su me e Parigi non sono mai riuscito a farlo, ho sempre detto che invece di una casa di campagna disponevo di una casa in una città estranea. (Calvino 1994b: 1212-1213) ${ }^{4}$

De esta manera, París se configura para Calvino como un allá, como un lugar "otro", desconectado de la realidad y de lo que lo rodea, en un tiempo que no tiene relación con el instante precedente, ni con el siguiente. Se trata de un lugar elegido como punto de observación desde donde mirar el mundo en lugar de participar de él. Es como si la imposibilidad de transformar París en un "paesaggio interiore" condujera al escritor italiano a reducir su relación con esta ciudad a un punto indistinto, caracterizado por esta distancia desde el objeto mirado, es decir Italia, y por la posibilidad de ganar en quietud y reposo para concentrarse exclusivamente sobre la página escrita. Juicio compartido con Luca Baranelli y Ernesto Ferrero, editores del Album Calvino, biografía que así describe la relación entre París y Calvino: "In fondo Parigi, pur cosí nettamente connotata, resta per Calvino il 'non luogo', la città in cui può sentirsi invisibile agli altri, l'imponente albero fronzuto da cui può osservare silenziosamente il mondo" (Baranelli y Ferrero 1995: 208).

Evidentemente, fuera de las metáforas literarias, París es para Calvino un lugar anónimo, neutro, como si su mente necesitara despojarlo de todas las incrustaciones culturales para que pueda hablar libremente y en forma nueva de ello, apuntando directamente a la experiencia personal.

Forse, identificandosi con la mia vicenda personale, con la vita quotidiana, perdendo quell'alone che è il riflesso culturale, letterario della sua immagine, Parigi potrebbe ridiventare una città interiore, e mi sarebbe possibile scriverne. Non sarebbe più la città di cui tutto è già stato detto, ma una città qualsiasi in cui mi trovo a vivere, una città senza nome. (Calvino 1994a: 191)

${ }^{4}$ La cita ha sido tomada del aparato filológico que acompaña al texto en el III volumen de Romanzi e racconti, que a su vez cita una entrevista de Daniele del Giudice a Calvino: "Un altrove da cui guardare I'universo", Paese sera, 7 gennaio 1978. En ella se hace referencia al final del Castello dei destini incrociati, obra cuya edición definitiva es de 1973 ( $v i d$. Calvino 1992: 596-602). 
Bajo esta perspectiva, el texto de Eremita a Parigi se eleva a un catálogo sui generis con función dúplice y antitética: en la medida en que su lista crece, acumulando las diferentes imágenes añadidas, al mismo tiempo propone excluirlas. Fijar en la página escrita la serie de imágenes que la capital francesa suscita bajo reflejo cultural y literario, no tanto para acordarse de ellas, sino para olvidarse, ponerlas de lado, en la esperanza de que una nueva y personal imagen pueda emerger desde el cúmulo de lo ya visto y de lo ya dicho.

Excavando en lo más profundo de las estratificaciones culturales de París y al mismo tiempo en su imaginario, Calvino cumple una operación que parece negar la razón de ser del catálogo mismo. Si un catálogo sirve como apoyo de la memoria, como ayuda escrita y visiva contra la posibilidad de olvidarse de algo importante, lo que constituye Calvino sirve más bien para lo contrario: coleccionar imágenes y luego olvidarlas en lugar de utilizarlas. Una operación que parece indirectamente previa y necesaria para que su prolífico imaginario pueda elaborar una imagen precisa que corresponda a "su" percepción de la capital francesa, compartida entre querencia de una soledad eremítica y tensión hacia una patria lejana.

En búsqueda de esta imagen, leemos nuevamente entre las líneas de Eremita a Parigi y notamos que el escritor italiano registra ya, a lo mejor sin darse cuenta, las huellas de su condición eremítica cuando afirma que "la mia scrivania è un po' come un'isola" (Calvino 1994a: 192), imagen que vuelve unida a su casa parisina donde se aparta para quedar solo.

[...] a Parigi ho la mia casa di campagna, nel senso che facendo lo scrittore una parte del mio lavoro la posso svolgere in solitudine, non importa dove, in una casa isolata in mezzo alla campagna, 0 in un'isola, e questa casa di campagna io ce I'ho nel bel mezzo di Parigi. E così, mentre la vita di relazione connessa col mio lavoro si svolge tutta in Italia, qui ci vengo quando posso e devo stare solo, cosa che a Parigi mi riesce sempre più facile. (Calvino 1994a: 192)

Será esta quizás la imagen personal de París, lo que significa verdaderamente para Calvino y para su propia producción escrita. Si Italia es percibida como un lugar de relaciones sociales (y diríamos de participación de una vida activa), París es una isla donde la vida activa queda en los márgenes para concentrase en "la vida contemplativa", que para Calvino coincide con su actividad de escritor. Exactamente lo que la imagen del eremita confirma. Por un jinete que abandona sus armas de lucha en el mundo, un eremita toma su plaza retirándose en una isla y blandiendo un bolígrafo.

La idea de la isla como lugar ideal, como espacio mítico fuera de la historia y de la geografía, forma de moderna Utopía buscada 
para alejarse y evadirse del mundo cotidiano, expresa perfectamente esta profunda exigencia de soledad vivida por el escritor italiano y coincide con la búsqueda de un sitio más idóneo donde concentrarse en la escritura, una vez consultados los libros bajo mano igual que el mundo observado desde lejos.

Podría resultar raro el acercamiento, más o menos consciente, cumplido por el imaginario de Calvino entre una ciudad como París y una isla, dado que normalmente una ciudad crece en un espacio determinado, geográficamente localizable y retiene una historia precisa que la modeliza hasta su conformación actual. Además una ciudad es la expresión de sus habitantes, del encuentro motivado por el intercambio (de relaciones, económico, profesional, etc.) entre ellos. Todo lo contrario de lo que significa una isla, donde la vida en soledad rechaza qualquier contacto humano.

En realidad, el acercamiento entre dos entidades tan distintas se verifica en Calvino porque esto no supone ningún problema para una mente como la suya, tan acostumbrada a seguir los cortocircuitos generados entre dos polos contrarios. Pensar según un modelo binario, donde se confrontan dos extremos, es sello constitutivo de la obra calviniana, que la critica ha subrayado desde hace tiempo y que se revela de nuevo en esta confrontación entre la aspiración hacia una isla ideal y la permanencia en una ciudad real. Todo el discurso seguido por nuestro análisis presenta signos evidentes de este sello, como por ejemplo, la división entre participación o consulta del mundo, que el imaginario calviniano proyecta en las dos imágenes del jinete y del eremita.

Sólo un punto queda por aclarar: una isla no es una torre de marfil, ni un castillo circundado de muros infranqueables, porque la posibilidad de contacto con el mundo externo es siempre posible, si se desea. Calvino renuncia a la exploración del mundo sabiendo bien que concentrarse en su escritura es una forma indirecta de participar en él. Indirecta, distinta por supuesto, no por eso menos válida, no por esto a desestimar, porque la escritura -añadiríamos la literaturacomo forma de contacto entre experiencia individual y mundo es un punto en el que Calvino creía verdaderamente. Así que no hay mucha distancia entre París y la imagen de una isla si el escritor se esfuerza continuamente en crear puentes entre ellas. Como veremos, Palomar constituye, en un cierto sentido, uno de estos puentes.

\section{París en Palomar}

Palomar ofrece a Calvino la tardía ocasión de centrarse en la ciudad de París como lugar donde ambientar algunos de sus escritos. Es precisamente en este libro en donde la capital francesa entra totalmente en las páginas no sólo como objeto de reflexión, entre biografía e historia de la literatura, sino como objeto literario, dentro de un mundo de ficción o pseudoficción. $Y$ precisamos pseudoficción 
porque, si no fuera por este nombre detrás del cual se oculta Calvino, Palomar seria un puro testigo de la vivencia calviniana, dado que el protagonista homónimo vive, a lo largo de todo el libro, las mismas experiencias que Calvino ha vivido en la vida real.

Si concentramos nuestra atención sobre la sección "Palomar fa la spesa" (Calvino 1992: 930-939), esta contiene tres textos ambientados en lugares parisinos definidos: una charcuterie ${ }^{5}$ en Un chilo e mezzo di grasso d'oca, una tienda de quesos en Il museo dei formaggi y una carnicería en Il marmo e il sangue (en este no hay una referencia cierta de París, pero nada impide pensar que se trata de una tienda de la capital). Ya el título de este último nos dirige directamente a una de las imágenes con la cual Calvino mira a esta ciudad: museo de museos, enorme contenedor de otros contenedores.

Así, siguiendo las aventuras urbanas de Palomar, lo sorprendemos mientras va de compras a varias tiendas de la capital y estas experiencias se transforman, o tendrían que transformarse, en un medium para la comprensión de la realidad circunstante. Porque si Palomar nace como un conjunto de textos de naturaleza híbrida entre la descripción, la meditación y la contemplación, único es el fin que su autor se propone: observar fragmentos de realidad en la tentativa de que estos nos restituyan un fundamento cierto y sólido para la construcción de modelos de interpretación de la realidad misma. Mirar para comprender: es este el refrán que se adapta perfectamente a estas páginas, incluidas aquellas en las cuales París y partes de ella la protagonizan.

No es una casualidad que el apellido del protagonista derive de un observatorio astronómico en California, como para subrayar esta tendencia a "sentirse" como un ojo curioso y escrutador, a la búsqueda de los detalles portadores de conocimiento. En la tienda de queso, por ejemplo, sus ojos se centran sobre la particularidad del apellido "Specialités fromagères", que evoca en Palomar "I'eredità di un sapere accumulato da una civiltà attraverso tutta la sua storia e geografia" (Calvino 1992: 933). Hasta la comida expuesta en esta tienda es vista como si fuera pieza de un museo y los clientes como si fueran visitantes detenidos más por el deseo de mirar lo que hay expuesto que por comprarlo: "Questo negozio è un museo: il signor Palomar visitandolo sente, come al Louvre, dietro ogni oggetto esposto la presenza della civiltà che gli ha dato forma e che da esso

\footnotetext{
${ }^{5}$ Hemos preferido utilizar el original francés por falta de un correspondiente preciso en castellano que indicase, en una única palabra, no sólo una tienda donde se pueden comprar productos a base de carne, sino también una tienda donde se prepara y se vende comida ya hecha para llevar. Calvino mismo prefiere utilizar el nombre francés, aunque en italiano existe "rosticceria" que se acerca mucho al tipo de tienda de la cual hablamos.
} 
prende forma" (Calvino 1992: 935). Por supuesto la metáfora museística tiene lugar al lado de otras aunadas por el concepto de mirar en estas tiendas como en obras de consulta, catálogos de nombres:

La formaggeria si presenta a Palomar come un'enciclopedia a un autodidatta; [...] Questo negozio è un dizionario; la lingua è il sistema dei formaggi nel suo insieme: una lingua la cui morfologia registra declinazioni e coniugazioni in innumerevoli varianti e il cui lessico presenta una ricchezza inesauribile di sinonimi, usi idiomatici, connotazioni e sfumature di significato, come tutte le lingue nutrite dall'apporto di cento dialetti. È una lingua fatta di cose; la nomenclatura ne è solo un aspetto esteriore, strumentale; ma per il signor Palomar impararsi un po' di nomenclatura resta sempre la prima misura da prendere se vuole fermare un momento le cose che scorrono davanti ai suoi occhi. (Calvino 1992: 934-935)

En realidad, poco a poco, a medida de que el texto se desarrolla, estas metáforas se configuran como un límite, un impedimento. Al llegar a la tienda de quesos, Palomar tiene en la cabeza una intención muy precisa: "stabilire la semplicità d'un rapporto fisico diretto tra uomo e formaggio" (Calvino 1992: 934), en total acuerdo con su búsqueda de sentido que pasa por la tentativa de establecer una relación verdadera con fragmentos mínimos de la realidad circundante. Palomar quiere entrar en la tienda y mirar la multitud de quesos expuestos como si fuera la primera vez. A lo mejor saborearlos uno a uno, fundando así su conocimiento personal sobre una experiencia directa que le permite establecer diferencias y analogías entre distintos tipos de quesos.

Aquí la intención parece ser perjudicada por la imposibilidad de pensar en el objeto, en este caso el queso, en sí mismo, en su condición real, es decir comida para satisfacer un instinto básico, porque las imágenes que se presentan en su cabeza son ya fruto de una experiencia cultural. Los apellidos, los significados, las historias de los quesos que contienen referencias implícitas de los campos en los cuales han sido pastoreadas las manadas: todas referencias culturales que impiden la consecución de una "vera conoscenza, che sta nell'esperienza dei sapori, fatta di memoria e d'immaginazione insieme, e in base ad essa soltanto potrebbe stabilire una scala di gusti e preferenze e curiosità ed esclusioni" (Calvino 1992: 935).

La situación no cambia en los otros dos textos. La charcuterie de Un chilo e mezzo di grasso d'oca contiene comida que la mirada de Palomar filtra como "un documento della storia della civiltà, [in] un oggetto da museo" (Calvino 1992: 932). Escenario análogo en II marmo e il sangue: toda una reflexión sobre la relación entre el hombre y su forma de supervivencia garantizada gracias a la matanza de animales para obtener alimento. Una reflexión que vive a 
lo largo de una comparación implícita: la carnicería es un templo donde antiguos rituales de matanza animal se perpetúan ahora en la época contemporánea. Las mismas referencias culturales que se interponían en el imaginario del autor para la elaboración de una imagen personal de la capital francesa hacen ahora de obstáculo hacia la apropiación, en un sentido cognoscitivo, de los objetos expuestos en sus tiendas. Actúan de interferencias entre un protagonista que quiere rehacer el proceso del conocimiento desde una observación puntual y precisa de elementos mínimos sin necesariamente pasar por algo ya dicho, ya visto. Pensándolo bien París opera en el imaginario del autor precisamente como Calvino había comentado a propósito de Balzac, condicionando todos los elementos que le pertenecen bajo la misma caracterización cultural.

Buscando otros ejemplos, a las tiendas como museos les suceden los zoológicos en la sección "Palomar allo zoo" (Calvino 1992: 940-948): lugares artificiales creados para la salvaguardia de especies naturales raras o para la conservación de los rastros de un pasado lejano. Son museos ellos también, donde la continuidad de la vida biológica ha sido encapsulada bajo vidrio, parada para ser mirada como momento intermedio entre la aparición de la vida sobre la tierra y el nacimiento del hombre. En particular, Palomar queda fascinado frente al espectáculo que el Jardin des Plantes de París le enseña en L'ordine degli squamati. Le atraen no sólo las diferentes tipologías de iguanas, sino también sus "vetrine illuminate":

È quest'ambiente, più che i rettili in sé, ciò che oscuramente attrae il signor Palomar? [...] Al di là del vetro d'ogni gabbia c'è il mondo di prima dell'uomo, o di dopo, a dimostrare che il mondo dell'uomo non è eterno e non è l'unico. [...] Ma dei mondi da cui l'uomo è escluso, ogni vetrina è un campione minimo, strappato da una continuità naturale che potrebbe non essere mai esistita, pochi metri cubi d'atmosfera che congegni elaborati mantengono a un certo grado di temperatura e d'umidità. Dunque ogni esemplare di questo bestiario antidiluviano è tenuto in vita artificialmente, quasi fosse un'ipotesi della mente, un prodotto dell'immaginazione, una costruzione del linguaggio, un'argomentazione paradossale intesa a dimostrare che il solo mondo vero è il nostro... (Calvino 1992: 947)

Al principio, no hay duda de que el mundo de las iguanas pertenece a la naturaleza, así como el del ser humano, ambos diferentes estadios en el proceso de evolución de la vida terrestre.

${ }^{6}$ Compárese este texto con el siguiente fragmento tomado de Eremita a Parigi: "Cosi nei miei itinerari di padre, di accompagnatore di mia figlia bambina, Parigi si apre alle consultazioni con i bestiari del Jardin des Plantes, i serpentari e i rettilarii in cui si crogiolano iguane e camaleonti, una fauna da ére preistoriche, e insieme la grotta dei draghi che la nostra civiltá si porta dietro" (Calvino 1994a: 197). 
Visto bajo vidrio, sin embargo, aquel mundo animal no parece tan natural como en realidad es. Es como si las vitrinas sugirieran que se trata de un mundo artificial mantenido mecánicamente con vida precisamente por el ser humano, como si fuera una emanación suya, un producto cultural, exactamente como el lenguaje. Es esta una imagen perturbadora que domina delante de los ojos del protagonista y que se insinúa en su visión hasta dejarlo enredado entre dos concepciones distintas. Otra vez la capacidad de deformación de un lugar como el Jardin des Plantes proporciona su acción de condicionante sobre una mente, la de Palomar/Calvino, impidiéndole pensar según su primera inclinación.

El eje a través del cual se distribuye esta reflexión es claramente entre naturaleza y cultura, sin que se asocie a estos dos polos un juicio de valor, positivo y negativo. Calvino se limita a constatar cómo la situación y los elementos en juego cambian según la perspectiva adoptada: la natural pone el mundo humano como biológica consecuencia y base para el desarrollo de otros mundos; la cultural sugiere el mundo humano como único $\mathrm{y}$, sobre todo, como el verdadero, sellando los otros como artificiales. Sospechamos que Calvino toma partido por la primera, porque sabe que el mundo humano es solamente uno de los mundos posibles entre una evolución biológica que va desde los organismos unicelulares hasta el microchip del ordenador.

\section{Conclusión}

A lo largo de nuestra investigación, hemos rastreado las modalidades con las cuales el imaginario de Italo Calvino elabora una serie de imágenes sobre la ciudad de París, dejándose influenciar por su presencia en la capital parisina y por la literatura pasada. Su prosa, biográfica y narrativa, muestra el uso de las mismas imágenes y cómo estas accionan en favor de una connotación cultural en detrimento de aquella natural. En particular, los cuentos analizados en Palomar confirman la dificultad del escritor italiano en la tentativa de establecer un contacto directo con la realidad que lo circunda; la misma dificultad que el ensayo Eremita a Parigi había evidenciado a la hora de intentar elaborar una imagen nueva de la ciudad de París, fuera del condicionamento proporcionado por las referencias históricas y literarias propias de la capital francesa.

Es sólo gracias a la identificación de la imagen de la isla como se hace posible introducir un elemento totalmente original y altamente revelador sobre la relación de Calvino con París, porque detrás de ella se asocian al mismo tiempo su condición de consulta del mundo, su exigencia de soledad para concentrarse en la escritura y su necesidad de vacío social. Se trata de una imagen que concentra múltiples implicaciones, no tanto por lo que aparentemente inspira, un encerramiento, una clausura, un apartarse de los eventos que 
mueven el mundo, cuanto por lo que realmente significa, una pausa de reflexión, una exigencia de concentración en la escritura como modalidad de influir bajo otra forma sobre aquellos mismos eventos. Escribir de la vida en lugar de vivirla no es una renuncia, sino una participación diferente que la página escrita puede garantizar igual que un engagement en primera línea. Así que la imagen de la isla como metáfora de la ciudad de París merece ser tenida como conclusión de este artículo más que cualquier otra, por este mensaje sobre la relación entre escritura y vida, entre literatura y mundo que tanta relevancia ha tenido para Calvino y para su obra.

\section{Bibliografía}

BARANELLI, Luca; y FERRERO, Ernesto (eds.) (1995): Album Calvino. Milano: Mondadori.

CALVINO, Italo (1972): Le città invisibili. Torino: Einaudi.

- (1992): Romanzi e Racconti, vol. II. Milano: Mondadori.

- (1994a): "Eremita a Parigi", "La mia città è New York", "Intervista di Maria Corti", en Eremita a Parigi, pp. 190-199; 265-270; 271-281. Milano: Mondadori.

- (1994b): Romanzi e Racconti, vol. III. Milano: Mondadori.

- (1995): "La città-romanzo in Balzac", en Saggi, vol. I, pp. 775-781. Milano: Mondadori. 